\title{
A OBSOLESCÊNCIA DO CONHECIMENTO EM PRESERVAÇÃO DIGITAL
}

Henrique Machado Santos
Mestrando do Programa de Pós-Graduação Profissional em Patrimônio Cultural
Universidade Federal de Santa Maria
benrique.hms.br@gmail.com
Daniel Flores
Universidade Federal de Santa Maria
dfloresbr@gmail.com


Doutor em Documentação

\section{Resumo}

Este estudo realiza uma reflexão sobre a gestão do conhecimento sobre preservação digital, com ênfase em preservar o conhecimento e mantê-lo acessível no longo prazo. Para isto é perpassada a relação entre gestão do conhecimento e preservação digital, assinalando pontos de convergência para um possível ciclo de retroalimentação. A metodologia utilizada consiste no levantamento bibliográfico de materiais previamente publicados, configurando-se como um artigo revisão de caráter assistemático. Dentre as contribuições mais relevantes deste estudo, ressalta-se que a obsolescência do conhecimento é um entrave tão complexo para a preservação digital, quanto a obsolescência de hardware e software, o que reforça a importância das práticas de gestão do conhecimento.

\section{Palavras-chave}

Preservação digital. Gestão do conhecimento. Obsolescência tecnológica. Obsolescência do conhecimento. Documento digital.

\section{INTRODUÇÃO}

Os constantes e desenfreados avanços das tecnologias da informação remodelam os meios de interação humana, de modo que os computadores exercem um papel intermediador da comunicação contemporânea. Diversas ferramentas tecnológicas surgem, trazendo consigo uma série de facilidades com relação ao uso e disseminação da informação. Como consequência, tem-se uma sociedade cada vez mais conectada, e intrinsecamente, dependente das tecnologias. Prova disso, são os dados, as informações e os documentos que estão sendo criados, armazenados e acessados em ambiente digital. Por vezes, tais registros não possuem um equivalente em suporte analógico, confiando assim, sua garantia de recuperação às mídias digitais.

Neste contexto, os acelerados avanços das tecnologias da informação têm como consequência, ciclos cada vez mais curtos de obsolescência tecnológica. Determinadas ferramentas de tecnologia da informação tornam-se obsoletas, e por consequência, são sobrepostas por novas ferramentas. Deste modo, as organizações têm necessidade de realizar esforços para se adaptarem ao constante e acelerado ciclo de transformações tecnológicas. Destaca-se que a busca por novas tecnologias visa essencialmente obter facilidades no processo de produção, armazenamento e acesso da informação, além disso, por vezes a tecnologia é considerada 
como um artefato capaz de aumentar o fator competitivo das organizações.

Entretanto, essa mudança consiste em um entrave para a estabilidade das informações registradas em ambiente digital, assim, uma atualização pode ser considerada um ponto crítico. O aparato tecnológico torna-se obsoleto, de modo que deverá ser substituído por um mais atual para garantir a continuidade do acesso. Desta forma, componentes de hardware, software e suportes estão em constante transição, tornando necessária a implementação de procedimentos técnicos que visem a preservação dos materiais digitais. Dentre estes procedimentos, podem-se destacar as estratégias de migração, emulação, encapsulamento e refrescamento. Além disso, as atividades de preservação digital devem ser vistas a luz de um planejamento estratégico, vislumbrando a manutenção da autenticidade e a garantia de acesso contínuo no longo prazo.

Observa-se que além de demandar custos às organizações, a constante evolução do aparato tecnológico, torna necessária a reestruturação da infraestrutura técnica. Isto resulta na necessidade de capacitar as pessoas envolvidas nas atividades de preservação através da contratação de especialistas e realização de cursos de capacitação para que a equipe possa se atualizar quanto às mudanças tecnológicas.

Em contrapartida, esta constante transformação do aparato tecnológico aliada à necessidade de capacitação contínua da equipe e às mudanças de pessoal, trazem implicitamente, a dispersão dos conhecimentos relativos às tecnologias utilizadas nas organizações. Como consequência, Os conhecimentos relativos ao uso de uma determinada técnica correm o risco de serem perdidos, de modo que a equipe necessite manusear uma tecnologia obsoleta da qual não se tem domínio. Tal entrave reside no fato de que as organizações produzem documentos $\mathrm{e}$ informações digitais em diferentes formatos, através de diversos softwares, em diversas versões, e que por vezes, não são padronizados e nem migrados para uma versão atual. Desta forma, as organizações detém a custódia de documentos produzidos em diversos contextos tecnológicos, de modo que poucos conhecimentos foram extraídos ou estão disponíveis para compreender o aparato tecnológico necessário à sua correta manutenção.

As discussões sobre preservação digital se limitam em sua maioria, a abordagens relacionadas à implementação de estratégias, sistemas informatizados e políticas de preservação. Logo, há pouca preocupação em se preservar o conhecimento sobre estas práticas, sendo que estes conhecimentos podem auxiliar no processo de preservação. Ressalta-se que a gestão do conhecimento atua como um processo organizacional de coleta, seleção, preservação e distribuição dos conhecimentos para uso posterior, seja no curto, no médio ou no longo prazo, desde que estes sejam úteis ao contexto da organização. Logo, a prática de gestão do conhecimento poderá auxiliar nas atividades de preservação digital, fornecendo informações referentes aos documentos digitais, bem como sobre especificidades das estratégias, sistemas e políticas de preservação implementadas.

Tendo em vista o exposto, este estudo propõe uma reflexão sobre a preservação do conhecimento decorrente das práticas de preservação digital, de modo que este conhecimento permaneça acessível no longo prazo. Desta forma, as discussões perpassam a relação entre gestão do conhecimento e preservação digital, identificando pontos de convergência e um possível ciclo de retroalimentação.

A metodologia utilizada consiste em um levantamento bibliográfico de materiais previamente publicados. Os dados são coletados a partir de livros, teses, dissertações e artigos científicos recuperados pela ferramenta de pesquisa Google Scholar. O recorte temporal enfatiza os trabalhos publicados nos últimos dez anos, período no qual as discussões em torno da preservação digital e da gestão do conhecimento foram acentuadas.

Desta forma, o presente artigo se classifica como de natureza básica, pois visa gerar conhecimento teórico sem se preocupar com a sua aplicação específica a uma 
realidade. Em relação aos seus procedimentos, pode ser classificado como um estudo bibliográfico que parte de uma revisão assistemática. O principal objetivo deste estudo consiste em proporcionar uma breve reflexão sobre o tema e salientar o ponto de vista dos autores no que se refere a identificar pontos de convergência entre preservação digital e gestão do conhecimento, os quais sejam capazes de proporcionar um ciclo de retroalimentação para ambas às práticas (GIL, 2010; LUNA, 1997; SILVA; MENEZES, 2005).

\section{A EVOLUÇÃO E A NECESSIDADE DOS REGISTOS DA INFORMAÇÃO}

A evolução do conhecimento ocorre através da interação entre a racionalidade do ser humano e os desafios oriundos da própria natureza, o que pode ser observado através da revolução neolítica (MENGARDA, 2014). Desta forma, foram gerados diversos conhecimentos pertinentes à manutenção da espécie, o que impulsionou a necessidade registar informações estratégicas.

$\mathrm{O}$ ato de transmitir o conhecimento é tido como uma atividade que se sucede desde as primeiras civilizações humanas que habitaram o Planeta. Logicamente, que em virtude dos avanços tecnológicos, os mecanismos de registro de hoje em dia são muito distintos daqueles do passado. A ruptura com os meios primitivos pode ser considerada como fruto de um processo de evolução natural, no qual os mecanismos de registro estiveram condicionados às tecnologias de suas respectivas épocas.

Os registros de conhecimento tiveram um longo processo de evolução, perpassando, os desenhos feitos nas paredes das cavernas até chegar às modernas tecnologias mediadas por computadores. Um ponto comum entre as civilizações primitivas e as contemporâneas, a ser destacado, é a necessidade do registro de conhecimentos por meio das tecnologias disponíveis na época. Não há como descrever com exatidão qual era a finalidade dos registros feitos pelas sociedades primitivas, mas sabe-se que o conhecimento registrado foi transmitido para as futuras gerações. Essa necessidade de registrar surge em virtude da fragilidade da memória humana, pois esta é falha, e assim, torna-se fundamental o registro das informações consideradas pertinentes.

A informação captada através dos sentidos passa a também ser expressa/registrada com o auxílio de ferramentas, objetos ou máquinas. Tais aspectos têm relação direta com a cultura, seja ela oral ou escrita, logo, diferentes profissões podem pesquisar, hierarquizar e dissecar a informação (LOPES, 1996). Como consequência, a transferência de mensagens através do tempo e do espaço potencializa o impacto do documento, o que se reflete na sua capacidade de organizar/sistematizar a informação, além de integrar a memória social da linguagem. As mensagens registradas na forma de documentos tornam-se autônomas de seus produtores, logo, é possível perenizar fatos, experiências e conhecimento, além de permitir o seu reuso (MARCONDES, 2010). Devido à necessidade de registrar fatos e conhecimentos, surgiu o documento, nada mais do que o meio de formalizar as informações fixando-as em um suporte físico. Dentre estes suportes, podem-se citar o pergaminho, o papiro e o papel, todos condicionados as tecnologias disponíveis da época.

Posteriormente, o documento se tornou mais complexo, em virtude do progresso científico e tecnológico ocorrido no século XIX. Neste período, ocorreram rápidas mudanças em diversos campos do conhecimento, bem como nas suas relações interdisciplinares, o que gerou o surgimento de novas profissões e especialidades (PAES, 2004). Logo, o surgimento dos documentos eletrônicos e digitais, ocorre em decorrência do advento de equipamentos como tocafitas, toca-discos, câmeras digitais, scanners e computadores, estes que por sua vez registram a informação em suportes como: Floppy-disk (Disquete), Compact Disc (CD), Digital Versatile Disc (DVD), Video Home System (VHS), Long Play (LP) e Hard Disk (HD).

A inserção das tecnologias da informação mudou os métodos de produção, difusão e acesso ao conhecimento, tendo seu 
reflexo nos documentos. Paralelamente, com a disseminação da Internet foi possível encurtar as fronteiras de tempo e espaço, e os documentos passaram a ser disseminados com maior praticidade (DORNELES; CORRÊA, 2013). Com relação às trocas de informação, observa-se que é a oferta de conteúdos quem cria uma demanda de usuários/receptores, pois estes desconhecem a qualidade dos conteúdos armazenados nos acervos. Embora os usuários/receptores conheçam o conteúdo com certa lucidez, não há como mensurar a precisão da informação desejada (BARRETO, 2009).

Há um valioso volume de documentos e conhecimentos sendo criados, armazenados e disseminados em formato digital. Destaca-se que parte significativa destes registros com valor social, cultural, informativo e histórico, não possui uma versão equivalente em meio tradicional, ou nem mesmo pode ser representada por um formato que não seja o digital. Tais fatos configuram um fator de dependência por tecnologias que interpretem e que garantam a autenticidade destes registros, a fim de salvaguardar este patrimônio para as gerações futuras.

Observa-se que todas as sociedades, em momento presente, foram contemporâneas, ou seja, catalisaram os conhecimentos oriundos de gerações passadas através da tecnologia disponível na época. E este modelo se repete até hoje, e provavelmente, seguirá por tempo indeterminado. Tais fatos reforçam a necessidade de preservar o conhecimento e a história das sociedades, de modo que sirva de base para criar novos conhecimentos, além de documentar a história das gerações passadas; do contrário não haverá o que oferecer para as gerações futuras.

\section{DA FRAGILIDADE IMPLÍCITA AO ESQUECIMENTO}

Vive-se em um contexto no qual um volume de dados cada vez maior está sendo armazenado em mídias que duram cada vez menos (CONWAY, 2001). Desta forma, documentos de diversas naturezas estão sendo produzidos pelas mais diversas organizações e pessoas, e por vezes, a produção não considera práticas de preservação em longo prazo.

Ressalta-se ainda que para acessar e interpretar corretamente os documentos armazenados em meio digital é preciso de um aparato tecnológico, o qual é composto por hardware, software e conhecimentos técnicos, sendo que todos estes, estão em constante mudança. Tais fatos vêm representando uma ameaça para a preservação em longo prazo, pois não há garantia de que os documentos serão preservados, acessados e interpretados de maneira correta.

Os documentos digitais não irão sobreviver de forma inerte, como acontece com os seus equivalentes em suportes analógicos (SAYÃO; SALES, 2012). Logo, podem ser perdidos com a mesma facilidade com que são gerados, isto implica em uma perda silenciosa e catastrófica, em virtude da grande capacidade de armazenamento das mídias (INNARELLI, 2009). Tais fatos demonstram que o patrimônio documental em dígitos binários é muito vulnerável, e está condicionado a diversas intempéries: erros de leitura em virtude da versão do software não ter compatibilidade retrospectiva; formatos de arquivo não compatíveis com a informação que precisa ser representada; inexistência de periférico de entrada; insuficiência de conhecimentos específicos para acessar a documentação; e corrupção de dados.

[...] o acesso e a usabilidade dos recursos informacionais digitais é impactado fortemente pela sua dependência a contextos tecnológicos específicos; esse fato gera uma área de tensão e complexidade na gestão de acervos digitais. A fragilidade estrutural da informação digital configura um dos maiores desafios a ser enfrentado pelos pesquisadores e profissionais das áreas de informação e de tantas outras áreas, neste começo de século. (SAYÃO, 2010b, p. 3).

Conforme observado, além da garantia de acesso, a utilização dos materiais 
digitais poderá ser afetada, por meio da perda de funcionalidade e características essenciais para a sua representação. Logo, há diversas ameaças que desafiam a longevidade dos documentos digitais, sendo necessário agir de forma coerente para não perder registros de valor ímpar e deixar lacunas irrecuperáveis na memória social.

\section{A PERDA DO CONHECIMENTO EM PRESERVAÇÃO DIGITAL}

O problema da preservação digital ainda está longe de ser resolvido, além disso, há diversas limitações em seu corpus teórico, o qual se encontra em desenvolvimento. Tais aspectos indicam a necessidade de maior aprofundamento teórico, da mesma forma, que o discurso da preservação deve ser orientado ao diálogo interdisciplinar.

A preservação digital vem gerando conhecimentos sobre as vulnerabilidades dos documentos, as estratégias e os sistemas informatizados. Uma parte deste conhecimento vem sendo registrada, principalmente, na forma de livros, artigos científicos e recomendações técnicas; desta forma, pode-se afirmar de maneira teórica, que estes conhecimentos já estão sendo preservados automaticamente. No entanto, existe outro conhecimento, decorrente das práticas de preservação digital, e que não vem recebendo a devida atenção, logo, poderá ser perdido com o tempo.

O conhecimento sobre preservação digital advém da reflexão e da experiência, como a grande maioria dos conhecimentos que a sociedade acumulou até hoje. O conhecimento que advém da reflexão é genérico e abrangente, podendo assim, ser aplicado a diversos acervos. No entanto, o conhecimento derivado da experiência é restrito e específico, e por vezes, também contempla uma realidade documental específica. Um exemplo de conhecimento genérico em preservação digital seriam os conceitos de preservação, repositório, metadados, estratégias e confiabilidade. Já como exemplos de conhecimentos específicos, podem-se destacar o manuseio dos sistemas MicroSoft Disk Operating System (MS-DOS) para acessar docu- mentos ou a emulação através de um determinado software. Este é um conhecimento que se limita a aplicações e lugares específicos.

O conhecimento genérico, mais abrangente, pode ser desenvolvido e discutido por todas as instituições e pesquisadores da preservação digital, em contrapartida, o conhecimento específico se restringe às peculiaridades do acervo. Assim, pode-se fazer a seguinte observação: um acervo relativamente recente não produz conhecimentos sobre plataformas antigas, mas um acervo antigo produz conhecimento sobre as plataformas novas e sobre as antigas. Desta forma, observa-se que a obsolescência tecnológica não se manifesta exclusivamente nas plataformas de hardware e software, deve-se ressaltar que o conhecimento, ao ficar restrito a determinados grupos, cai em desuso e tornase obsoleto.

Neste contexto, observa-se que as instituições que preservam documentos digitais precisam fazer a gestão do conhecimento da preservação digital, caso contrário correm o risco de não conhecerem os métodos para continuar preservando seus próprios conteúdos. Este entrave é inserido em virtude da renovação da equipe responsável pelas atividades de preservação, pois há grandes possibilidades de se perder conhecimentos no longo prazo. Destaca-se que para evitar ou mesmo minimizar este problema é preciso registrar o conhecimento e preservar estes registros, o que gera um ciclo de retroalimentação entre a preservação digital e a gestão do conhecimento.

Em uma breve visita às reflexões sobre gestão do conhecimento é possível encontrar diversos estudos convergindo Administração e Ciência da Informação (BARTALO, 2008; DE SORDI, 2008; INNARELLI, 2012b; LUZ, 2010; 2015; ROSINI; PALMISANO, 2003; SANTOS, 2009; SANTOS; FLORES, 2015b; SILVA FILHO; SILVA, 2005; SOUSA, 2008), o que reforça seu caráter interdisciplinar. No entanto, poucos estudos permitem vislumbrar as atividades de gestão do conhecimento na preservação digital. 
Santos (2009) apresenta a gestão do conhecimento em face ás sete funções arquivísticas (produção, aquisição, classificação, avaliação, conservação, descrição e difusão). Já Santos e Flores (2015b) realçam a importância da gestão do conhecimento, e apontam que ela pode exercer um papel fundamental quando aliada a preservação digital, gerando assim um ciclo de retroalimentação. E De Sordi (2008) realiza uma análise de 15 qualidades da informação que são pertinentes em relação a sua utilização no contexto administrativo. Desta forma, o autor perpassa as seguintes qualidades: a abrangência/escopo; a integridade; acurácia/veracidade; confidencialidade/privacidade; disponibilidade; atualida$\mathrm{de} /$ temporalidade; ineditismo/raridade; contextualização; precisão; confiabilidade; originalidade; existência; pertinência/agregação de valor; identidade; e audiência (DE SORDI, 2008).

No entanto, estes estudos não abordam a preservação dos conhecimentos sobre a preservação digital de forma satisfatória, sendo necessário aprofundar esta questão em face da sua complexidade. Em outras palavras é preciso ir além dos estudos sobre informação, seja com relação ao seu reuso, seu potencial estratégico ou de tomada de decisões. Da mesma forma, é preciso ultrapassar os limites $\mathrm{da}$ obsolescência tecnológica em nível de hardware e software, e ter em vista a obsolescência do conhecimento na preservação digital, para que assim se proponha uma gestão do conhecimento mais ampla e integrada a fim de minimizar as diversas intempéries do meio digital.

\section{CONVERGÊNCIAS ENTRE GESTÃO DO CONHECIMENTO E PRESERVAÇÃO DIGITAL}

A gestão do conhecimento consiste no conjunto de procedimentos e atividades que tem objetivo de identificar, registrar e gerir o conhecimento das pessoas garantindo o seu reuso e sua difusão (SANTOS, 2009). Desta forma, o conhecimento se constitui num importante ativo organizacional e por isto precisa ser preservado de forma eficaz.

Observa-se que investir na gestão do conhecimento somente será viável para as organizações que pensam no longo prazo (ROSINI; PALMISANO, 2003). Logo, as instituições de memória como arquivos, bibliotecas e centros de documentação e informação se enquadram nesta perspectiva. Tal fato evidencia que a gestão do conhecimento irá corroborar para o desenvolvimento das atividades destas instituições, fornecendo maior precisão, confiabilidade e facilitando o acesso às informações de interesse organizacional.

Com o aprimoramento dos processos de produção humana, surge a economia de conhecimento, focada nos meios de comunicação, técnicas de produção e de transmissão do conhecimento (INAZAWA, 2009). Assim, observa-se que a retenção de conhecimento tornou-se um aspecto essencial para compreender o sucesso das organizações. Da mesma forma, a gestão do capital humano amplia o conhecimento coletivo e este, por sua vez, contribui para a organização (SILVA FILHO; SILVA, 2005). Em uma analogia simples, pode-se observar que as atividades de preservação digital dependem de conhecimentos específicos, e o seu compartilhamento contribui para enriquecer o plano de preservação. Neste sentido, gerir o conhecimento da preservação digital irá contribuir para a implementação de procedimentos mais adequados, reduzindo os custos e aumentando a eficiência.

A informação, diferentemente de outros patrimônios, não obedece às mesmas leis econômicas. Ela possui suas peculiaridades, as quais devem ser compreendidas para que esta possa ser gerida de maneira correta (IKEMATU, 2001). Além disso, para a informação em meio digital acrescenta-se um conjunto de complexidades e especificidades oriundas de sua natureza digital. Há novas perspectivas de uso e difusão, e muitas incertezas quanto a sua preservação.

É preciso manter níveis de qualidade sobre o conhecimento gerido, e para isto, uma boa gestão do conhecimento deve considerar a produção, a seleção, a transforma- 
ção, a distribuição, a avaliação e a preservação do conhecimento. E como resultado, constitui-se um valioso ativo organizacional (SANTOS; FLORES, 2015b). Para isto, salienta-se a necessidade de uma cultura organizacional favorável à gestão do conhecimento, gerando níveis de aprendizado compatíveis com as mudanças aceleradas. Tais aspectos requerem a transformação da organização como um todo, assim, uma cultura organizacional que privilegia a aprendizagem irá potencializar o processo de gestão do conhecimento (INAZAWA, 2009).

A geração do conhecimento ocorre diante da ciência do fato, da verdade e da informação, a união destes aspectos, junto às experiências anteriores, são processados de acordo com a capacidade de raciocínio e introspecção do indivíduo. Por isto, a cognição depende de uma reflexão realizada pelo indivíduo a priori (DE SORDI, 2008). Este procedimento pode facilmente ser aplicado às atividades de preservação digital, logo, é preciso que o profissional capacitado faça o relato de sua reflexão e posteriormente seja avaliado como um conhecimento relevante ou não para as atividades de preservação digital.

O conhecimento sempre desempenhou e desempenha papel fundamental na evolução do mundo, das empresas e das pessoas. Sua aquisição, aplicação, armazenagem e recuperação sempre representam estímulo para as conquistas no decorrer dos tempos, na evolução dos seres humanos. Assim, o saber sobre determinada ação ou fato, ou até sobre determinada coisa, não proporciona, por si só, maior poder de competição para uma organização - só será real e significativa se aliado, gerido e aplicado. (FACHIN et al., 2009).

Assim, a gestão do conhecimento e a preservação digital podem constituir uma base para as atividades realizadas nos acervos, apontando alternativas, além de possibilitar o compartilhamento de conhecimentos entre parceiros. $\mathrm{O}$ conhecimento sobre preservação digital poderá ser formado a partir de informações sobre formatos de arquivo, sistemas informatizados e estratégias de preservação, auxiliando tanto a pesquisa, quanto a prática (SANTOS; FLORES, 2015a).

Tendo em vista a convergência entre as práticas de preservação digital e gestão do conhecimento, os acervos podem adotar uma abordagem integrada entre si, para estabelecer um ciclo de retroalimentação. Logo, observa-se que as práticas de preservação digital irão auxiliar a preservação do conhecimento gerido, e a gestão do conhecimento irá gerenciar o conhecimento sobre as práticas de preservação digital. Desta forma, obtém-se uma relação de mutualismo onde uma se usa da outra ao mesmo tempo em que lhe concede melhorias.

\section{BOAS PRÁTICAS DE GESTÃO DO CONHECIMENTO NO LONGO PRAZO}

Paralelamente a necessidade de se definir políticas institucionais de preservação e implementar estratégias e sistemas informatizados, é preciso desenvolver uma base de conhecimentos sobre as diversas tecnologias presentes no processo de preservação em longo prazo. Desta forma, será possível fazer o reuso da informação, empregando conhecimentos pré-existentes para auxiliar nas atividades de preservação digital. Sendo assim, analisam-se aspectos relacionados às estratégias de preservação digital, tanto as estruturais, quanto as operacionais; e os sistemas informatizados para preservação e acesso em longo prazo.

\subsection{Estratégias estruturais}

As estratégias estruturais consistem na preparação do ambiente de preservação digital definindo questões como infraestrutura física e tecnológica adequada, bem como o planejamento das atividades em longo prazo. Neste sentido, podem-se destacar algumas dimensões onde é preciso implementar a gestão do conhecimento, dentre elas: no uso de padrões, metadados, segurança, custos relacionados e planejamento. 
O uso de padrões nos acervos se constitui como uma estratégia relevante sendo apontado por diversos estudos, dentre eles: Innarelli (2012a), Interpares (2007), Santos, Flores e Hedlund (2015) e Thomaz (2004). Observa-se que trabalhar como uma variedade reduzida de formatos implica em minimizar os riscos de obsolescência tecnológica. No entanto, é preciso conhecer a estrutura destes formatos, quando possível. Neste sentido as práticas de gestão do conhecimento podem auxiliar a preservação digital, registrando, por exemplo, informações relacionadas aos formatos de arquivos. É fundamental manter informações como o tipo do padrão, de facto ou de jure, tais especificações poderão auxiliar, por exemplo, em uma migração ou emulação no futuro.

O esquema de metadados também corrobora na preservação de longo prazo, sendo considerado essencial para evidenciar a autenticidade dos documentos preservados. Tal fato pode ser observado em diversos estudos: Innarelli (2012a), Interpares (2007), Márdero Arellano (2004, 2008), Rondinelli (2005), Santos e Flores (2015a), Saramago (2004), Sayão (2010b), Thomaz (2004). O esquema de metadados por si só já é capaz de registrar diversas informações consideradas relevantes e indispensáveis à presunção da autenticidade dos documentos digitais. Entretanto, é preciso que este mesmo esquema registre informações sobre si mesmo, como por exemplo, licenças as quais está sujeito e especificidades técnicas. Além disso, o próprio código fonte deve estar documentado e disponível ao acervo. Desta forma, as transformações tecnológicas do futuro poderão ser auxiliadas por uma descrição com riqueza de detalhes, a qual deverá estar armazenada em uma base de conhecimento segura.

Ressalta-se que a política de segurança da organização deve estar desenvolvida em um plano de segurança, o qual irá auxiliar os auditores a analisarem os procedimentos praticados, sinalizando as principais vulnerabilidades e providências para minimizá-las. Logo, este plano de segurança também irá servir como instrumento de trabalho organizacional (PEREIRA, 2005). Em sua essên- cia, a definição de uma política de segurança da informação deve considerar aspectos legais, organizacionais, humanos e tecnológicos, com a finalidade de garantir a autenticidade dos documentos digitais e o sigilo da informação. Da mesma forma, deve prevenir contra perdas, sinistros e intervenções não autorizadas/nem documentadas (BRASIL, 2004).

No contexto organizacional, a segurança é ativo essencial à salvaguarda das informações custodiadas, seja por instituições públicas ou privadas. As informações concebidas em ambientes digitais requerem tecnologias específicas que garantam suas qualidades de autenticidade e confidencialidade (DORNELES; CORREAA, 2013). Logo, deve-se contemplar tanto o controle de acesso, quanto as rotinas de backup dos sistemas utilizados e dos documentos inseridos nestes sistemas; garantindo assim, a capacidade de recuperação de desastres, além de definir as permissões de acesso aos diferentes perfis de usuários.

No entanto, é preciso que as informações sobre estes procedimentos estejam disponíveis aos preservadores no futuro. Isto porque, muito provavelmente, será preciso aderir a novos métodos de controle de acesso, a novos sistemas de preservação e novas rotinas de backup. E a necessidade de migrar para uma nova tecnologia poderá causar perdas nas informações de conteúdo dos documentos em virtude da ausência de um conhecimento específico. Em resumo, é preciso conhecer a tecnologia antiga para fazer uma migração eficiente para a nova tecnologia escolhida, observa-se neste ponto que, com o passar dos tempos, o próprio conhecimento se tornará obsoleto, pois as velhas tecnologias caem em desuso.

Neste sentido, o planejamento é outro aspecto essencial dentre as estratégias estruturais, auxiliando na definição de metas e na mensurar custos no longo prazo. No entanto, as etapas do planejamento devem estar preservadas, acessíveis e inteligíveis aos futuros integrantes do programa de preservação digital. Isto porque a execução do planejamento é uma etapa linear e, quaisquer 
interrupções acarretarão riscos à confiabilidade do plano de preservação.

É fundamental reconhecer inicialmente quais são as ameaças intrínsecas aos conteúdos digitais. Esta análise pode gerar benefícios às instituições com relação à administração de recursos financeiros para implementação e manutenção de sistemas e processos operacionais. Logo, para uma eficiente gestão da informação é preciso identificar as vulnerabilidades de forma antecipada, ou mesmo possuir conhecimento necessário para solucioná-las ou minimizálas (BELARMINO; ARAÚJO, 2014). O planejamento de um programa de preservação digital sustentável envolve o prévio entendimento, em especial, entre produtores e entidades depositantes, considerando questões como a normatização e a disponibilização da informação digital (CAMPOS, 2002).

Além disso, no planejamento se definem questões como o uso de padrões, os metadados, os procedimentos de segurança da informação e os custos relacionados às atividades de preservação. Tais aspectos realçam a importância de se preservar estes conhecimentos, os quais têm um valor estratégico fundamental para garantir a longevidade do sistema de preservação digital.

\subsection{Estratégias operacionais}

Diversos estudos vêm debatendo a implementação de estratégias operacionais, dentre estes se podem destacar: Corrêa (2010), Ferreira (2006), Grácio e Fadel (2010), Iglésia Franch (2008), Lopes (2008), Márdero Arellano (2004; 2008), Rothenberg (1999), Santos (2005), Saramago (2002), Thibodeau (2002), Thomaz (2004) e Thomaz e Soares (2004). Estes estudos concentram-se na análise e comparação de estratégias como: a preservação de tecnologia, o refrescamento, a emulação, o encapsulamento e a migração. Dentre suas principais conclusões destaca-se que nenhuma estratégia consegue solucionar todos os problemas de preservação em longo prazo.

No entanto, é preciso desenvolver uma base de conhecimentos sobre as estratégias, apresar de não se ter uma solução definitiva para os problemas oriundos da obsolescência tecnológica. Isto porque a sua implementação é uma prioridade conforme destacado por Márdero Arellano (2008), observando que a ausência de procedimentos de preservação coloca os documentos digitais em risco, não havendo nenhuma garantia de acesso em longo prazo.

Em se tratando de preservação em longo prazo, pode-se observar que diversas estratégias serão implementadas pelos acervos, tendo resultados positivos e negativos para cada contexto tecnológico em que foram aplicadas. Tais experiências possuem um valor imensurável, pois podem nortear a implementação das mesmas estratégias no futuro, contribuindo para uma economia de recursos e evitando a obsolescência do conhecimento. Como é amplamente conhecido, ressalta-se que a memória humana é falha, e assim, surge a necessidade de se registrar as informações. Além disso, no plano organizacional, as pessoas são peças transitórias, porém o acervo a ser preservado é de longo prazo, senão permanente.

É possível potencializar as atividades do acervo com atividades simples como o registro do desempenho de determinados conversores e emuladores, a abrangência dos padrões de metadados e a compatibilidade dos formatos de arquivo. De tal forma, o reuso dessas informações irá corroborar estabelecer uma divisão entre $o$ que deu certo $e$ o que não deu certo. Neste sentido, a ideia que se propõe é a identificação e descrição dos procedimentos de preservação digital realizados pelo acervo, desta forma, se estabelece um ciclo de retroalimentação, o qual deriva das próprias experiências da organização.

Em linhas gerais, observa-se que as estratégias operacionais podem ter diversas variações dependendo do software que as executam e dos formatos de arquivo em questão. Desta forma, o registro destas experiências irá contribuir para otimização de atividades específicas no âmbito interno do acervo com um grau de confiabilidade elevado. 


\subsection{Sistemas informatizados de preservação}

Para preservar documentos digitais autênticos é preciso implementar sistemas informatizados que garantam a custódia confiável (THIBODEAU, 2002). Estes sistemas têm por finalidade realizar a manutenção da autenticidade, além de garantir o acesso a documentos fidedignos no longo prazo (WEBB, 2003). Para tal, é preciso contemplar uma ampla variedade de formatos de arquivo, além de possibilitar acesso aos usuários (HEDSTROM, 1998).

Neste contexto, a implementação de sistemas informatizados deverá considerar aspectos relacionados à sua própria longevidade, pois o ideal é que os sistemas sejam estáveis, sejam de código aberto e recebam atualizações periódicas, para que assim, não se tornem obsoletos em curtos períodos de tempo. Deste modo, buscam-se reunir estas características nos sistemas, a fim de reduzir a frequência de migração para novas plataformas. Assim, ressalta-se que é possível minimizar os efeitos da obsolescência tecnológica logo na fase do planejamento de longo prazo.

Dentre os sistemas informatizados para preservação e acesso, pode-se destacar a implementação de repositórios digitais. Esta é uma tendência que vem sendo discutida e aprofundada em diversos estudos, dentre eles: Belarmino e Araújo (2014), Fernal e Vechiato (2013), Ferreira (2006), Lopes (2008), Márdero Arellano (2008), Márdero Arellano e Leite (2009), Ramalho, Ferreira, Castro, Faria, Barbedo e Corujo (2007), Saramago (2004), Sayão (2010a) e Thomaz (2007).

O repositório digital consiste em um serviço de armazenamento de materiais digitais, tendo capacidade de preservar e gerenciar estes materiais em longo prazo, além de prover acesso apropriado (MÁRDERO ARELLANO, 2008). No entanto, o repositório não consiste na finalidade da preservação digital, ele é um dos meios para gerenciar os procedimentos de preservação em alto nível. Logo, é preciso que o repositório seja regido por normas definidas nas políticas de preservação, e essas normas precisam ser difundidas à comunidade de usuários a fim de gerar confiança.

O êxito de um repositório digital só pode ser abordado no seu contexto específico de atuação. Assim, os critérios para o sucesso devem ser derivados de sua missão e de uma declaração de propósito previamente definida nas políticas institucionais (THIBODEAU, 2007). Desta forma, a longevidade dos documentos em meio digital, seja enquanto fontes de pesquisa, ou instrumentos da moderna administração; está diretamente relacionada aos métodos empregados na sua preservação. Logo, além das estratégias estruturais e operacionais, é preciso seguir uma política organizacional voltada à preservação digital em longo prazo e ainda implementar um repositório digital em conformidade com o que foi previamente definido na política (SANTOS; FLORES, 2016).

Pode-se definir a preservação digital como uma gestão de riscos, assim, busca-se mensurar as incertezas da manutenção e usabilidade de objetos digitais autênticos em riscos quantificáveis. O repositório digital terá como finalidade, minimizar os riscos que impedem a sua capacidade de fornecer acesso à informação digital autêntica. Logo, o êxito no trabalho prestado pelo repositório será a qualidade das informações que fornece a sua comunidade designada (DCC/DCP, 2007). Com isto, o repositório deverá ter uma equipe com qualificação e formação necessárias, envolvida em um programa de desenvolvimento contínuo. A equipe deverá ter um número de integrantes suficiente para garantir a realização de todos os serviços e funcionalidades oferecidos. (BRASIL, 2015). Desta forma, conforme Rocha (2015) o repositório digital será entendido como:

[...] um ambiente tecnológico complexo para o armazenamento e a gestão de materiais digitais. Este ambiente é composto por uma solução informatizada na qual se captura, armazena, preserva e se provê acesso aos objetos de informação digitais. Um repositório digital é, então, um complexo formado por elementos de hardware (dispositivos 
de armazenamento), software, serviços, coleção de informação digital e metadados associados a esses objetos de informação. Todo este conjunto tem como objetivo apoiar a gestão de materiais digitais pelo tempo que seja necessário. (ROCHA, 2015, p. 183).

Diversos estudos apontam a implementação do Open Archival Information System (OAIS) como uma prática essencial (MÁRDERO ARELLANO, 2008; SARAMAGO, 2004; SAYÃO, 2010a; THOMAZ, 2006; THOMAZ; SOARES, 2004). O OAIS é um modelo de referência conceitual que especifica requisitos para um repositório digital com a finalidade de preservar e oferecer acesso à determinada comunidade de usuários (CCSDS, 2012).

Neste contexto, a implementação de repositórios digitais em conformidade com o modelo OAIS vem sendo considerada como uma prática altamente recomendada para o longo prazo. No entanto, nada impede que as soluções de software utilizadas para construir este sistema fiquem obsoletas. E desta forma, o conhecimento referente a cada aplicação de software também se tornará obsoleto, dificultando assim, o processo de recuperação das informações preservadas.

Observa-se que o modelo OAIS não prescreve implementação, e desta forma, os acervos são livres para utilizar as tecnologias mais adequadas para suas respectivas realidades documentais. Assim, poderá haver um conjunto de softwares que corroboram para constituir o repositório em conformidade com o OAIS, sejam eles emuladores, conversores, mecanismos para verificação de trilhas de auditoria ou sincronizadores de backup. Embora o OAIS vislumbre a preservação de documentos digitais no longo prazo, ressalta-se que a longevidade do próprio OAIS pode não atingir o longo prazo, em virtude de mudanças nos métodos adotados pela comunidade de preservação.

\subsection{Gestão do conhecimento e preserva- ção digital: um modelo convergente}

O conhecimento organizacional não se restringe a documentos, bases de dados e sistemas informatizados, ele também pode ser encontrado nos processos, nas práticas e diretamente nas pessoas. Logo, o fato das organizações terem interesse no conhecimento se justifica por este apoiar suas funções e atividades (ROSINI; PALMISANO, 2003). Desta forma, o conhecimento sobre as atividades de preservação digital não se restringe aos sistemas para gestão e ao repositório digital. Tais conhecimentos estão na execução das estratégias, nos padrões de metadados, nas definições da política institucional e nos indivíduos que executam as atividades de preservação digital.

Figura 1 - Ciclo de retroalimentação

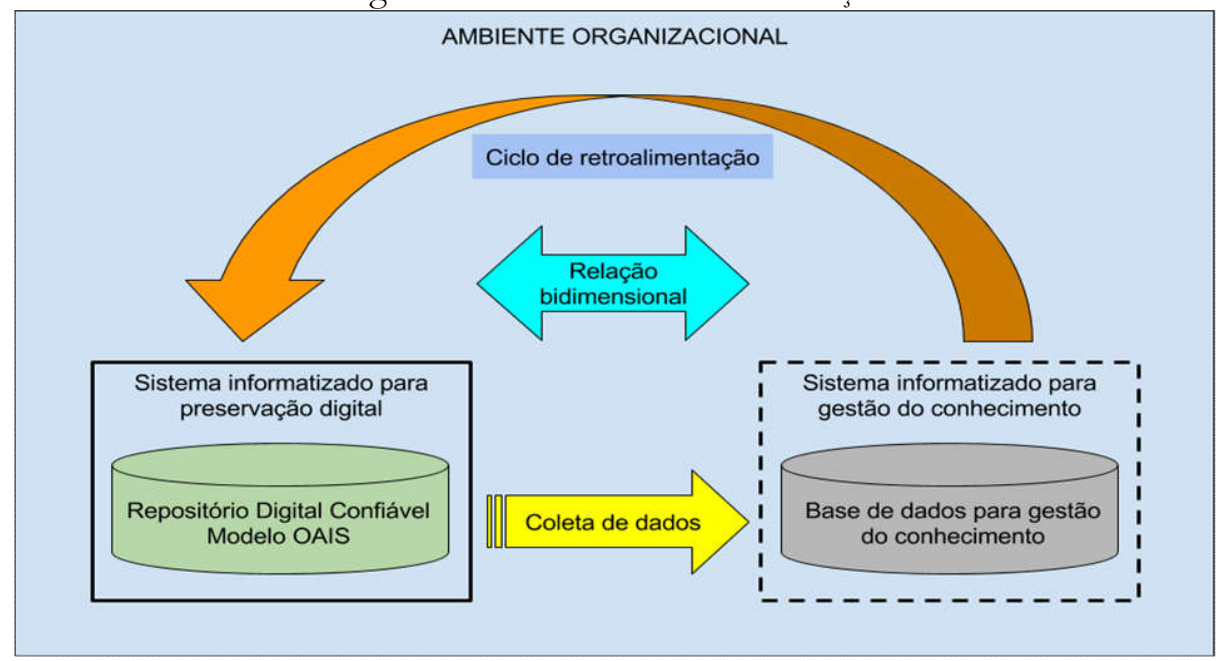

Fonte: elaborado pelos autores, 2018. 
Considerando as questões abordadas, a "Figura 1 - Ciclo de retroalimentação" apresenta uma relação bidirecional entre as práticas de preservação digital e gestão do conhecimento no ambiente organizacional. Desta forma, estabelece um fluxo de coleta e outro de retroalimentação.

Neste esquema, o conhecimento advindo das práticas de preservação digital executadas no âmbito do repositório digital confiável é coletado e armazenado em uma base de conhecimentos. A gestão deste conhecimento poderá auxiliar futuras ações visto que a base de conhecimento estabelece um ciclo de retroalimentação com o repositório digital confiável. Isto implica em gerir conhecimento de preservação digital que poderão ser requisitados futuramente por outros indivíduos. Desta forma, o conhecimento sobre preservação digital produzido no âmbito organizacional será preservado e disponibilizado, rotinas que minimizam a perda de conhecimentos e corroboram para a preservação dos documentos digitais no longo prazo.

A gestão do conhecimento da preservação digital poderá fornecer uma base sólida sobre as práticas da organização, indicar as melhores alternativas, além possibilitar a troca de conhecimentos entre organizações parceiras. Uma base de conhecimentos sobre preservação digital poderá compartilhar informações para auxiliar as práticas do acervo, dentre elas, informações sobre formatos de arquivo, sistemas de gestão e estratégias de preservação (SANTOS; FLORES, 2015a).

Um repositório digital armazenará documentos produzidos em diversas épocas, tendo assim, uma diversidade de formatos de arquivo produzidos por diferentes versões de software. Isto implica em ter uma diversidade de conhecimentos para o tratamento técnico dos documentos digitais produzidos. Logo, este conhecimento precisa ser coletado na medida em que é produzido, minimizando as chances de perdas com o passar do tempo. Neste ponto a gestão do conhecimento corrobora para reunir os conhecimentos úteis para uso posterior, e ga- rante que conhecimentos específicos não sejam perdidos no contexto organizacional.

Desta forma, a preservação do conhecimento se configura como uma importante estratégia para auxiliar no desenvolvimento de novos modelos conceituais no futuro, caso isto seja necessário. $\mathrm{O}$ conhecimento sobre o ambiente de preservação proporciona liberdade aos gestores da informação e segurança aos conteúdos preservados nos acervos. Com isto, os repositórios se adaptarão melhor as mudanças tecnológicas e de pessoal, facilitando a execução de estratégias e a compreensão das informações de conteúdo.

\section{CONSIDERAÇÕES FINAIS}

Definitivamente, a obsolescência é o maior entrave para a preservação digital, isto porque ela se manifesta em nível de hardware, software, suportes e até mesmo sobre o conhecimento técnico sobre preservação digital. Observa-se que os constantes avanços das tecnologias da informação catalisam os ciclos de obsolescência em todos os níveis, e desta forma, adicionam complexidade à preservação dos documentos digitais.

O conhecimento pode ser entendido como uma matéria prima para a preservação digital, sem ele não há como recomendar ou prever quais procedimentos devem ser implementados. Neste ponto, é essencial preservar informações sobre os emuladores, conversores, licenças de uso, planos de preservação, padrões de metadados, formatos de arquivo, entre outros. Caso estas informações sejam perdidas, corre-se o risco de se reaprender a preservar, o que seria catastrófi$\mathrm{co}$, pois a preservação digital ainda tem muito a se desenvolver para chegar ao nível da preservação tradicional de documentos em suportes analógicos. Desta forma, a preservação do conhecimento torna-se essencial para garantir os avanços das práticas no longo prazo, logo, a perda de conhecimento configura-se como um retrocesso que deixará muitas lacunas na memória das sociedades contemporâneas, causando um prejuízo imensurável. 
A solução mais apropriada para os acervos digitais é preservar o conhecimento sobre a preservação digital. Isto pode ser realizado através do registro de experiências nas quais se obtiveram êxito ou não, desta forma, tem-se as melhores práticas para determinada situação e evitam-se cometer os mesmos equívocos de outrora. Com isto, um possível sistema integrado de preservação digital e gestão do conhecimento será composto por duas bases de armazenamento de informações, sendo que uma será responsável pela custódia documental, enquanto outra será a base de conhecimentos relacionados a preservação digital.

Desta forma, o papel da gestão do conhecimento consiste em registrar o conhecimento das práticas de preservação digital, enquanto que a preservação digital, por sua vez, irá preservar os registros criados pela gestão do conhecimento, além dos materiais custodiados. A sincronia entre estas práticas permite estabelecer um ciclo de retroalimentação bidirecional, o qual possibilita o reuso da informação e minimizará os riscos de obsolescência do conhecimento.

Em linhas gerais, este estudo demonstrou que a obsolescência do conhecimento está tão enraizada na preservação digital quanto à obsolescência de hardware, software e suporte. E para minimizar os seus efeitos é preciso realizar estudos interdisciplinares e implementar soluções de certa complexidade, como é o caso do ciclo de retroalimentação entre preservação digital e gestão do conhecimento. Logo, a convergência entre preservação digital e gestão do conhecimento deve ser abordada de forma integrada, através de sistemas informatizados para gerir suas práticas e identificar conhecimentos utilizáveis no longo prazo.

\title{
THE OBSOLESCENCE OF KNOWLEDGE IN DIGITAL PRESERVATION
}

\begin{abstract}
This study makes a reflection on the knowledge management about digital preservation, with emphasis on preserving the knowledge and keeps it handy in the long run. For this is pervaded the relationship between knowledge management and digital preservation, noting convergence points for a possible feedback loop. The methodology consists of bibliographic materials previously published by setting up as a review article unsystematic. Among the most important contributions of this study, it is noteworthy that the obsolescence of knowledge is an obstacle as complex for digital preservation, as the hardware and software obsolescence, which reinforces the importance of knowledge management practices.
\end{abstract}

\section{Keywords}

Digital preservation. Knowledge management. Technological obsolescence. Obsolescence of knowledge. Digital record. Artigo recebido em 20/05/2017 e aceito para publicação em 29/04/2018

\section{REFERÊNCIAS}

BARRETO, A. A. Os documentos de amanhã: a metáfora, a escrita e a leitura nas narrativas em formato digital. DataGramaZero, v. 10, n. 1, 2009, Rio de Janeiro. Disponível em:

$<$ http://ridi.ibict.br/handle/123456789/15

9. Acesso em: 19 dez. 2017.

BARTOLO, L. A importância das estratégias de estudo para uma aprendizagem mais significativa na área de arquivologia. In: BARTOLO, L.; MORENO, N. A (Orgs.).
Gestão em Arquivologia: abordagens múltiplas. Londrina: Eduel, 2008, p. 89-118.

BELARMINO, V. F.; ARAÚJO, W. J. Análisis de vulnerabilidades computacionales en repositorios digitales. Biblios: Revista de Bibliotecología y Ciencias de la Información, n. 56, p. 1-18, 2014, Lima. Disponível em: <http: //biblios.pitt.edu/ojs/index.php/biblios/art icle/view/169>. Acesso em: 02 set. 2016.

BRASIL. CONSELHO NACIONAL DE ARQUIVOS. Câmara Técnica de documen- 
tos eletrônicos. Carta para a preservação do patrimônio arquivístico digital. Rio de Janeiro: Arquivo Nacional, 2004. Disponível em:

$<$ http://www.conarq.arquivonacional.gov.b $\mathrm{r} /$ Media/publicacoes/cartapreservpatrimarq digitalconarq2004.pdf $>$. Acesso em: 10 ago. 2014.

BRASIL. CONSELHO NACIONAL DE ARQUIVOS. Câmara Técnica de documentos eletrônicos. Diretrizes para a implementação de repositórios arquivísticos digitais confiáveis - RDC-Arq. Rio de Janeiro: Arquivo Nacional, 2015. Disponível em:

$<$ http://www.conarq.gov.br/images/public acoes_textos/diretrizes_rdc_arq.pdf $>$. Acesso em: 10 jun. 2016.

CAMPOS, F. M. Informação digital: um novo património a preservar. Cadernos Bad, n. 2, 2003, Lisboa. Disponível em: $<$ http://www.bad.pt/publicacoes/index.ph $\mathrm{p} /$ cadernos/article/view/861>. Acesso em: 21 dez. 2017.

CONSULTATIVE COMMITTEE FOR SPACE DATA SYSTEM (CCSDS). Reference model for an Open Archival Information System (OAIS). Washington: Management Council of the Consultative Committee for Space Data Systems, 2012. Disponível em: $<$ http://public.ccsds.org/publications/archi ve $/ 650 \mathrm{x} 0 \mathrm{~m} 2 . \mathrm{pdf}>$. Acesso em: 13 mai. 2016.

CONWAY, P. Preservação no universo digital. 2. Ed. Rio de Janeiro: Arquivo Nacional, 2001.

CORRÊA, A. M. G. Preservação digital: autenticidade e integridade de documentos em bibliotecas digitais de teses e dissertações. Dissertação de Mestrado, Universidade de São Paulo: São Paulo, 2010.

DE SORDI, J. O. Administração da informação: fundamentos e práticas para uma nova gestão do conhecimento. São Paulo: Saraiva, 2008.

DIGITAL CURATION CENTRE; DIGITAL PRESERVATION EUROPE (DCC/DPE). Digital Repository Audit Method Based On Risk Assessment (DRAMBORA). v. 1.0, Fev., 2007. Disponível em: $<$ http://www.repositoryaudit.eu/download >. Acesso em: 13 nov. 2014.

DORNELES, S. L.; CORRÊA, R. F. Gestão de documentos digitais em aplicações de Certificação digital. Informação arquivística, v. 2, n. 2, 2013, Rio de Janeiro. Disponível em:

$<$ http://www.aaerj.org.br/ojs/index.php/in formacaoarquivistica/article/view/28>. Acesso em: 15 jan. 2016.

FACHIN, G. R. B.; STUMM, J.; COMARELLA, R. L.; FIALHO, F. A. P.; SANTOS, N. Gestão do conhecimento e a visão cognitiva dos repositórios institucionais.

Perspectivas em Ciência da Informação, v. 14, n. 2, p. 220-236, 2009. Belo Horizonte. Disponível em:

$<$ http://portaldeperiodicos.eci.ufmg.br/ind ex.php/pci/article/view/212>. Acesso em: 09 fev. 2017.

FERNAL, A.; VECHIATO, F. L. Repositórios digitais como ambientes de atuação do arquivista: um estudo dos princípios arquivísticos e da preservação digital nesse contexto. Informação@Profissões, v. 2, n. 1, p. 103-122, 2014, Londrina. Disponível em: $<$ http://www.uel.br/revistas/uel/index.php /infoprof/article/view/17272>. Acesso em: 10 jan. 2016.

FERREIRA, M. Introdução à preservação digital: conceitos, estratégias e actuais consensos. Portugal: Escola de Engenharia da Universidade do Minho, 2006. Disponível em:

$<$ https://repositorium.sdum.uminho.pt/bits tream/1822/5820/1/livro.pdf $>$. Acesso em: 02 ago. 2016. 
GIL, A. C. Como elaborar projetos de pesquisa. 5. ed. São Paulo: Atlas, 2010.

GRÁCIO, J. C. A.; FADEL, B. Estratégias de preservação digital. In: VALENTIM, M. (Org.). Gestão, mediação e uso da informação. São Paulo: Unesp, 2010, p. 59-83.

HEDSTROM, M. Digital preservation: a time bomb for digital libraries. Computers and the Humanities, v. 31, n. 3, p. 189202, 1998, Netherlands. Disponível em: $<$ http://deepblue.lib.umich.edu/bitstream/ 2027.42/42573/1/10579_2004_Article_153 071.pdf>. Acesso em: 01 out. 2016.

IGLESIAS FRANCH, D. La fotografía digital en los archivos. Gijón: Trea, 2008.

IKEMATU, R. S. Gestão de metadados: sua evolução na tecnologia da informação. DataGramaZero, v. 2, n. 6, 2001, Rio de Janeiro. Disponível em:

$<$ http://www.datagramazero.org.br/dez01/ Art_02.htm>. Acesso em: 20 de dez. 2016.

INAZAWA, F. K. O papel da cultura organizacional e da aprendizagem para sucesso da gestão do conhecimento. Perspectivas em Ciência da Informação, v. 14, n. 3, p. 206-220, 2009. Belo Horizonte. Disponível em:

$<$ http://portaldeperiodicos.eci.ufmg.br/ind ex.php/pci/article/view/726>. Acesso em: 08 fev. 2017.

INNARELLI, H. C. Instrumenta 2: preservação de documentos digitais. São Paulo: ARQ-SP, 2012a.

Preservação digital e seus dez mandamentos. In: SANTOS, V. B. (Org.). Arquivística: temas contemporâneos. Distrito Federal: SENAC, 2009. p. 21-75.

C. Preservação digital: a gestão e a preservação do conhecimento explícito digital em instituições arquivísticas. InCID:

Revista de Ciência da Informação e Documentação, v. 3, n. 2, p. 48-63, 2012b, Ribeirão Preto. Disponível em:
$<$ http://www.revistas.usp.br/incid/article/v iew/48653>. Acesso: 28 dez. 2014.

INTERNATIONAL RESEARCH ON PERMANENT AUTHENTIC RECORDS IN ELECTRONIC SYSTEMS (INTERPARES). Diretrizes do Produtor. A elaboração e a manutenção de materiais digitais: diretrizes para indivíduos. Tradução: Arquivo Nacional e Câmara dos Deputados, 2007. Disponível em:

$<$ http://www.interpares.org/ip2/display_fil e.cfm?doc=ip2_creator_guidelines_booklet-portuguese.pdf>. Acesso: 09 ago. 2016.

LOPES, L. C. A informação e os arquivos: teorias e práticas. Niterói: EDUFF, 1996.

LOPES, V. Preservação digital. Universidade do Minho, 2008. Disponível em: $<$ http://www.vitorlopes.com/Trabalhos/Pr eservacao_Digital-Vitor_Lopes.pdf $>$. Acesso: 28 mar. 2016.

LUNA, S. V. Planejamento de pesquisa: uma introdução. São Paulo: Educ, 1997.

LUZ, C. Arquivologia 2.0: a informação digital humana. Florianópolis: Bookess, 2010.

Primitivos digitais: uma abordagem arquivística. Salvador: Bravos, 2015.

MARCONDES, C. H. Linguagem e documento: fundamentos evolutivos e culturais da Ciência da Informação. Perspectivas em Ciência da Informação, v. 15, n. 2, p 2-21, maio./ago. 2010. Disponível em: $<$ http://portaldeperiodicos.eci.ufmg.br/ind ex.php/pci/article/view/1019>. Acesso em: 19 dez. 2017.

MÁRDERO ARELLANO, M. Á. Critérios para a preservação digital da informação científica. 2008. 354f. Tese (Doutorado em Ciência da Informação), Universidade Federal de Brasília, Departamento de Ciência da Informação, 2008. Disponível em: $<$ http://bdtd.bce.unb.br/tedesimplificado/t 
de_busca/arquivo.php?codArquivo $=4547>$. Acesso em: 10 jan. 2016.

Preservação de documentos digitais. Ciência da Informação, v. 33, n. 2, p. 15-27, 2004, Brasília. Disponível em: $<$ http://revista.ibict.br/ciinf/article/view/1 043>. Acesso em: 25 jul. 2016.

.; LEITE, F. C. L. Acesso aberto à informação científica e o problema da preservação digital. Biblios: Revista de Bibliotecología y Ciencias de la Información, v. 35, p. 01-11, 2009, Lima. Disponível em: <http://repositorio.unb.br/handle/10482/4 937>. Acesso em: 30 out. 2016.

MENGARDA, E. J. Linguagem e Cognição: enfoque psicolinguístico para compreender e superar as dificuldades em leitura e escrita. Santa Maria: UFSM, 2014.

PAES, M. L. Arquivo: teoria e prática. 3. Ed. Rio de Janeiro: FGV, 2004.

PEREIRA, P. J. F. Segurança da informação digital. Cadernos BAD, n. 1, p. 66-80, 2005, Lisboa. Disponível em:

$<$ http://www.bad.pt/publicacoes/index.ph $\mathrm{p} /$ cadernos/article/view/822>. Acesso em: 20 dez. 2017.

RAMALHO, J. C.; FERREIRA, M.; CASTRO, R.; FARIA, L.; BARBEDO, F.; CORUJO, L. XML e preservação digital. In: XATA - XML aplicações e tecnologias associadas, Lisboa, 2007. Disponível em: $<$ http://repositorium.sdum.uminho.pt/han dle/1822/6224>. Acesso em: 20 out. 2016.

ROCHA, C. L. Repositórios para a preservação de documentos arquivísticos digitais. Acervo, Rio de Janeiro, v. 28, n. 2, p. 180191, 2015. Disponível em:

$<$ http://revista.arquivonacional.gov.br/inde x.php/revistaacervo/article/view/608>. Acesso em: 21 dez. 2017.

RONDINELLI, R. C. Gerenciamento arquivístico de documentos eletrônicos: uma abordagem teórica da diplomática ar- quivística contemporânea. 4. ed. Rio de Janeiro: FGV, 2005.

ROSINI, A. M.; PALMISANO, A. Administração de sistemas de informação e a gestão do conhecimento. São Paulo: Pioneira Thomson Learning, 2003.

ROTHENBERG, J. Avoiding Technological Quicksand: Finding a Viable Technical Foundation for Digital Preservation. Council on Library and Information Resources, 1999. Disponível em: $<$ http://www.clir.org/pubs/reports/rothen berg/pub77.pdf>. Acesso em: 24 set. 2016.

SANTOS, H. M.; FLORES, D. O documento arquivístico digital enquanto fonte de pesquisa. Perspectivas em Ciência da Informação, v. 21, n. 4, p. 1-17, 2016, Belo Horizonte. Disponível em: $<$ http://portaldeperiodicos.eci.ufmg.br/ind ex.php/pci/article/view/2688>. Acesso em: 21 jan. 2017.

Políticas de preservação digital para documentos arquivísticos. Perspectivas em Ciência da Informação, v. 20, n. 4, p. 197 217, 2015a, Belo Horizonte. Disponível em: $<$ http://portaldeperiodicos.eci.ufmg.br/ind ex.php/pci/article/view/2542>. Acesso em: 21 dez. 2016.

Um diálogo entre arquivo, conhecimento e tecnologia. Biblios: Revista de Bibliotecología y Ciencias de la Información, v. 60, p. 55-62, 2015b, Lima. Disponível em: $<$ http://biblios.pitt.edu/ojs/index.php/bibli os/article/view/215>. Acesso em: 04 jul. 2016.

SANTOS, H. M.; HEDLUND, D. C.; FLORES, D. Padronização dos formatos de arquivo: um caminho para preservar os documentos arquivísticos digitais. Biblionline, v. 11, n. 1, p. 158-172, 2015, João Pessoa. Disponível em: $<$ http://periodicos.ufpb.br/ojs2/index.php /biblio/article/view/25157>. Acesso em: 20 jan. 2016. 
SANTOS, V. B. A prática arquivística em tempos de gestão do conhecimento. In: (Org.). Arquivística: temas contemporâneos: classificação, preservação digital e gestão do conhecimento. 3. ed. Distrito Federal: Senac, 2009, p. 175-223.

Gestão de documentos eletrônicos: uma visão arquivística. 2. Ed. Brasília: Abarq, 2005.

SARAMAGO, M. L. Metadados para preservação digital e aplicação do modelo OAIS. In: CONGRESSO NACIONAL DE BIBLIOTECÁRIOS, ARQUIVISTAS E DOCUMENTALISTAS, 8., 2004, Estoril. Actas... Estoril, 2004. Disponível em: $<$ http://www.bad.pt/publicacoes/index.ph $\mathrm{p} /$ congressosbad/article/view/640>. Acesso em: 04 jul. 2016.

Preservação digital a longo prazo: boas práticas e estratégias. Cadernos BAD, n. 2, 2002, Lisboa. Disponível em:

$<$ http://www.bad.pt/publicacoes/index.ph $\mathrm{p} /$ cadernos/article/view/866>. Acesso em: 10 fev. 2016.

SAYÃO, L. F. Repositórios digitais confiáveis para a preservação de periódicos eletrônicos científicos. Ponto de Acesso, v. 4, n. 3, p. 68-94, 2010a, Salvador. Disponível em: $<$ http://www.portalseer.ufba.br/index.php/ revistaici/article/view/4709>. Acesso em: 08 de ago. 2016.

Uma outra face dos metadados: informações para a gestão da preservação digital. Encontros Bibli: revista eletrônica de biblioteconomia e Ciência da Informação, v. 15, n. 30, p. 1-31, 2010b, Florianópolis. Disponível em: $<$ https://periodicos.ufsc.br/index.php/eb/ article/view/1518-2924.2010v15n30p1>. Acesso em: 08 fev. 2016.

.; SALES, L. F. Curadoria digital: um novo patamar para preservação de dados digitais de pesquisa. Informação \& sociedade: estudos, João Pessoa, v. 22, n. 3, p.
179-191, set./dez. 2012. Disponível em: $<$ http://www.ies.ufpb.br/ojs2/index.php/ie s/article/view/12224>. Acesso em: $11 \mathrm{dez}$. 2017.

SILVA FILHO, C. F. D.; SILVA, L. F. Da aprendizagem à gestão do conhecimento. In: . (Org.). Tecnologia da informação para a gestão do conhecimento: teoria e estudos em organizações. Campinas: Alínea, 2005.

SILVA, E. L.; MENEZES, E. M. Metodologia da pesquisa e elaboração de dissertação. 4. ed. Florianópolis: UFSC, 2005.

SOUSA, R. T. B. D. Em busca de um instrumental teórico-metodológico para a construção de instrumentos de classificação de documentos de arquivo. In: BARTOLO, L.; MORENO, N. A. (Orgs.). Gestão em Arquivologia: abordagens múltiplas. Londrina: Eduel, 2008, p. 12-52.

THIBODEAU, K. If you build it, will it fly? Criteria for success in a digital repository.

Journal of digital information, v. 8, n. 2, 2007. Disponível em:

$<$ http://journals.tdl.org/jodi/index.php/jod i/article/view/197/174>. Acesso em: 21 dez. 2017.

Overview of technological approaches to digital preservation and challenges in coming years. CLIR and Library of Congress, 2002. Disponível em: $<$ http://www.clir.org/pubs/reports/pub10 7/thibodeau.html>. Acesso em: 09 nov. 2016.

THOMAZ, K. P. A preservação de documentos eletrônicos de caráter arquivístico: novos desafios, velhos problemas. 2004. 389p. Tese (Doutorado em Ciência da Informação), Escola de Ciência da Informação. Universidade Federal de Minas Gerais, 2004. Disponível em:<http://www.bibliotecadigital.ufmg.br/ dspace/bitstream/handle/1843/VALA68ZRKF/doutorado__katia_de_padua_tho maz.pdf>. Acesso em: 20 jun. 2016. 
Gestão e preservação de documentos eletrônicos de arquivo: revisão de literatura-parte 2. Arquivística.net, v. 2, n. 1, p. 114-131, 2006, Rio de Janeiro. Disponível em:<www.brapci.ufpr.br/download.php?dd $0=6733$ > . Acesso em: 09 set. 2016.

Repositórios digitais confiáveis e certificação. Arquivística.net, v. 3, n. 1, p. 80-89, 2007, Rio de Janeiro. Disponível em: $<$ http://www.brapci.inf.br/_repositorio/20 10/05/pdf_fed0720dbb_0010726.pdf>. Acesso em: 05 set. 2016. .; SOARES, A. J. A preservação digital e o modelo de referência Open Archival
Information System (OAIS). DataGramaZero, v. 5, n. 1, 2004, Rio de Janeiro. Disponível em:

$<$ http://www.brapci.inf.br/index.php/articl e/view/0000007749/6f3e125671cfe45b7fdd ce5de6cf37f8/>. Acesso em: 10 dez. 2017.

WEBB, C. Guidelines for the preservation of digital heritage. Biblioteca Nacional da Austrália, 2003. Disponível em: <http://unesdoc.unesco.org/images/0013/ 001300/130071e.pdf $>$. Acesso em: 17 ago. 2016. 